\section{Discussion}

Both these patients closely resemble those that have been described before. In three of Werther's cases amyloidosis had contributed substantially to the cause of death. Symptoms of enteritis had preceded the diagnosis of amyloidosis by intervals of eight, ten and fourteen years and death had occurred in each case before the age of forty years. Two of the patients had died of uraemia and one had died during an episode of acute pancreatitis which had developed during a nephrotic stage of his chronic renal disease. The occurrence of acute pancreatitis in Case 1 is of some interest as this is an uncommon disease at this age (Rocker and Bartlett, 1953). This may possibly be related to steroid therapy as the present case had had several years' treatment with prednisone and Werther's case had had a short course of ACTH. This association has been suggested several times in the past (Nelp, 1961; Carone and Mebow, 1957).

The development of renal involvement by amyloidosis, as shown by proteinuria, is a bad prognostic sign and Werther's three cases all died within two years of discovery of this. Case 2 appears to have done relatively well in this respect.

It is well known that amyloidosis is frequently associated with chronic inflammatory disease which is sometimes of a tuberculous nature and that it is sometimes difficult for the pathologist to distinguish intestinal tuberculosis from regional enteritis. Both the above cases were investigated extensively with this in mind without any evidence of tuberculosis being found. Antituberculous drugs were given because it was the routine to treat cases of regional enteritis in this way, but neither case received an adequate course of treatment for tuberculosis.

On the other hand it is hardly surprising that regional enteritis, which is a disease characterised by the persistence of lesions of an inflammatory type, should be associated with amyloidosis. In fact, Chapin, Scudamore, Bagenstoss and Bargen (1956) in an analysis of post-mortem material obtained at routine post-mortem on thirty-nine cases of regional enteritis found two cases with severe renal amyloidosis.
They suggest that this complication may be much more common than is generally recognized although it may not necessarily contribute to the patient's death.

In view of the poor prognosis of a patient who develops manifestations of renal amyloidosis, Werther's recommendation that this complication should provide an indication for further surgery seems reasonable. However, it will seldom be applicable as these patients have usually had severe prolonged enteritis with several previous operations.

\section{Summary}

Two patients with regional enteritis who developed renal failure due to amyloidosis are described. The literature is reviewed briefly and the hope expressed that this association will be recognized more frequently in the future.

Thanks are due to Dr. Avery Jones, under whom both these patients were admitted, for permission to publish these cases and for his help with the preparation of this paper.

Briggs, G. W. (1961): Amyloidosis, Ann. intern

Med., 55, 943.
CARONE, F. A., and Liebow, A. A. (1957): Acute Pancreatic Lesions in Patients Treated wit A.C.T.H. and Adrenal Corticoids, New Engl. $\frac{\mathscr{P}}{2}$ Med., 257, 690.

Chapin, L. E., Scudamore, H. H., Bagenstoss, A. H., and BARGEN, J. A. (1956): Regional Enteritis, Associated Urinal Changes, Gastroenterology, 30, 404.

CoHEN, H., and Fishman, A. P. (1949): Regional Enteritis and Amyloidosis, ibid, 12, 502.

NeLP, W. B. (1961): Acute Pancreatitis Associated with Steroid Therapy, Arch. intern. Med., 108, 702.

Palmer, W. L., KirSner, J. B., Goldgraber, M. B., and FUENTES, S. S. (1963): Diseases of the Liver in Regional Enteritis, Amer. J. med. Sci., 246, 663.

ROKER, W., and BARTLETT, M. K. (1953): Acute Pancreatitis, New Engl. J. Med., 249, 751.

WERTHER, J. L., SCHAPIRA, A., RUBinSteIN, O., and JANOWITZ, H. D. (1960): Amyloidosis in Regional Enteritis, Amer. J. Med., 29, 416.

\title{
VILLOUS ADENOMA OF THE RECTUM WITH ELECTROLYTE DEPLETION, DIABETES AND HYPOGONADSIM
}

\author{
J. K. BAMford, M.B., B.CHIR., \\ Lately Medical Registrar \\ B. W. T. Pender, F.R.C.S., \\ Surgeon \\ The Chelmsford Hospitals
}

H.-J. B. Galbraith, M.D., M.R.C.P.,

VILLOUS tumour of the lower bowel has been recognised as a clinical entity for over a century; Quain used this descriptive term when writing in 1855. However it was not until 1954 that the association of a state of severe fluid and electrolyte depletion with villous adenoma of the rectum 
was first reported (McKittrick and Wheelock, 1954). Recently Eisenberg, Kolb, Yam and Godt (1964) and Shamblin, Huft, Waugh and Moertal (1962) have each reported a case and between them reviewed 25 other cases described in the literature.

The common clinical features of the uncomplicated condition of villous tumour of the rectum have been described by Ewing (1950). The most characteristic is the passage per rectum of clear and rather viscid mucoid material. 'The presence of a villous growth high up in the rectum is often first suggested on proctoscopy when withdrawal of the obturator is followed by the escape of just such a collection of clear mucus.' The mucus may become mixed with faeces, so that the patient complains only of diarrhoea, or it may escape involuntarily from the anus, so that incontinence is complained of. Rarely, flecks of blood and fragments of tumour tissue may be passed per rectum or the tumour itself may prolapse. Similar tumours occur higher up in the bowel but the great majority lie in the rectum or sigmoid colon. However, because of the physical characters of the lesions their presence has been missed on digital examination even when within reach. Symptoms are usually present for many years before diagnosis and the patients are usually elderly. Although clinically the tumours appear benign, malignant degeneration in part of the growth is common.

The tumours which are associated with states of electrolyte deficiency do not differ macroscopically or histologically from those in uncomplicated cases except that they are larger. Local symptoms tend to be present for longer in the complicated group. The watery mucoid discharge, which may reach a volume of over 3 litres in 24 hours, has a high electrolyte content. The sodium concentration usually approaches that in the serum. The potassium concentration is vastly greater in the mucoid fluid than in serum (3.7-5.4 $\mathrm{mEq}$./1.) or in normal fæces (10-15 mEq.1). concentrations of $40 \mathrm{mEq}$./1. being frequently recorded in cases with electrolyte depletion; the rectal fluid from one patient contained $180 \mathrm{mEq}$. of potassium per litre (Haverkon Van Rijsewijk, $1961)$ and from another $80 \mathrm{mEq}$. per litre (Starr, Mueller and McKittrick, 1956). The mechanism of this differential secretion of potassium from the tumour is not known but Little (1964) has shown that large quantities of potassium can be lost from apparently normal colonic mucosa above an obstruction. The pathological physiology of the electrolyte loss from villous tumours is well discussed by Shnitka, Friedman, Kidd and MacKenzie (1961), and Duthie and Atwell (1963). The latter have reported studies on isolated loops of intestine in patients undergoing surgery for villous papillomata or other lesions of the large gut. On the basis of their experimental evidence, they suggest that the losses of water and electrolytes from the papillomata are due to an intrinsic difference in the cells of these tumours and not simply to the increased surface area.

Electrolyte balance is usually maintained, if rather critically, until an additional loss occurs, such as from vomiting or diarrhoea, or until there is interference with dietary intake, as for example, in preparation for some clinical or radiological investigation. Despite the large quantities of potassium in the rectal mucous discharge, and the very frequent presence of hypokalaemia, symptoms of potassium deficiency, such as muscle weakness and cardiac irregularity, are rarely the most prominent. The majority of the patients reported have presented in acute episodes of dehydration with hypotensive circulatory collapse. Despite intensive parenteral therapy it has sometimes proved impossible to correct the electrolyte deficiences completely, in which circumstance it is advisable not to delay surgery.

Many of the patients with villous tumours of the rectum or sigmoid colon who are free of all but local symptoms must be in a delicate state of electrolyte balance. Biochemical examination of the serum is obviously an essential preliminary to operation in all patients with this lesion.

\section{Case Report}

Mrs. E. F., a housewife of 67 years, was admitted as an emergency on the 10th January, 1964, the family doctor suspecting that she might have had a myocardial infarction. One week previously, follow ing an upper respiratory infection, she complained of a vague pain in the front of the chest and suffered from vomiting and diarrhoa. There had been some loss of weight. The general practitioner noticed a mental sluggishness and suspected myxœema. Shortly before admission she became drowsy, with a blood pressure of $90 / 60 \mathrm{~mm}$. Hg. Then and subsequently the patient was unable to amplify this story and in particular gave no consistent account of her menstrual history. Her husband did not know whether his wife had ever menstruated or not. There were no children.

On examination she was drowsy and at times almost unresponsive. The temperature was $95^{\circ} \mathrm{F}\left(35^{\circ} \mathrm{C}\right)$. The pulse rate was 80 per minute, respiration rate 20 per minute. The systolic blood pressure was $80 \mathrm{~mm}$. and the diastolic blood pressure was unrecordable. There was a generalized brown pigmentation of the skin but the oral mucosa was not affected. The state of the subcutaneous tissues suggested some dehydration but was otherwise normal. The breasts were not developed and the nipples were pre-pubertal in type. Scalp hair was fine, axillary hair absent and pubic hair very scanty. There was slight tenderness in the right hypochondrium. Nothing abnormal was felt on rectal examination. Tendon reflexes were absent in the legs, those in the arms were present and showed no delay in relaxation. There was no retinopathy. Catheterization yielded only a few millilitres of urine which showed an acid reaction, a specific gravity of 1010 , a trace of albumin (30 mg./100 ml.), $1 \%$ reducing substances (to Clinitest), and no ketones. The height, measured subsequently, was $5 \mathrm{ft}$. The ECG showed incomplete right bundle branch block with multiple ventricular extrasystoles. 
A preliminary diagnosis of hypopituitary crisis was made. After venous blood had been taken for biochemical examination, treatment was begun with an immediate intravenous injection of $200 \mathrm{mg}$. of hydrocortisone sodium succinate and with an intravenous infusion of $5 \%$ dextrose in isotonic saline.

\section{Investigations:}

Blood urea 445 , glucose $252 \mathrm{mg}$. $/ 100 \mathrm{ml}$; serum $\mathrm{Na} \mathrm{102,} \mathrm{K} \mathrm{4.4,} \mathrm{Cl} 45, \mathrm{HCO}_{3} 13$ mEq. $/ 1$.

In view of the high blood glucose concentration the infusion was continued with saline alone. During the first 12 hours she received 1 litre of isotonic saline, half a litre of one-sixth molar sodium lactate and $800 \mathrm{mg}$. of hydrocortisone sodium succinate intravenously. At the end of this period the blood pressure had risen to $90 / 50$ and laboratory investigations were:-PCV: $50 \%$. Hb: 15.5 g. $/ 100 \mathrm{ml}$. RBC: 5,600,000 per cu. mm. Platelets: 728,000 per cu. mm. WBC: 20,600 per cu. mm. Polys.: $88 \%$. Lymphs.: $12 \%$. ESR: $12 \mathrm{~mm} . / \mathrm{hr}$. (Westergren). Blood urea: 454, glucose $282 \mathrm{mg}$. $/ 100 \mathrm{ml}$.; serum Na. 133, $\mathrm{K} 4.4, \mathrm{Cl} 51, \mathrm{HCO}_{3} 13$ mEq. $/ 1$.

\section{Treatment:}

Aldosterone was given, $0.5 \mathrm{mg}$. intravenously and $0.5 \mathrm{mg}$. intramuscularly, and hydrocortisone $200 \mathrm{mg}$. was given every hour. Twelve hours later the blood pressure had risen to $110 / 70$ and the dose of intravenous hydrocortisone was reduced to $100 \mathrm{mg}$. every four hours. The dose was further reduced, to $100 \mathrm{mg}$. every six hours, 36 hours after admission, at which time the serum potassium had fallen to $2.7 \mathrm{mEq}$./1. Administration of potassium orally and intravenously was begun. Oral cortisone $50 \mathrm{mg}$. every eight hours was substituted on the fifth day but within 24 hours the blood pressure fell to $100 / 60$, and then, despite resumption of intravenous hydrocortisone therapy, to 70/40. Normal levels were restored after $700 \mathrm{mg}$. of hydrocortisone had been given during a 12-hour period. From the seventh day (16.1.64) onwards oral cortisone was given, at first $75 \mathrm{mg}$. eight-hourly, reducing gradually to $50 \mathrm{mg}$ eight-hourly. With these doses, the blood pressure remained at satisfactory levels.

Twenty-four hours after admission the patient became able to take fluid orally in addition to the intravenous infusion, but it was not until four-and-ahalf days after admission that a satisfactory balance between the fluid intake and output was achieved, although jugular venous engorgement and some œedema of the sacral pad were then apparent. By this time, over 21 litres had been given by the oral and intravenous routes, and a total fluid output of about 11 litres had been recorded (i.e. excluding insensible losses in sweat and expired air). The blood urea had fallen steadily by this date (15.1.64) to $244 \mathrm{mg} . / 100 \mathrm{ml}$. and the PCV to $35 \%$. However, despite the administration since admission of over $1600 \mathrm{mEq}$. of sodium intravenously (as isotonic sodium chloride or lactate), of $160 \mathrm{mEq}$. of potassium intravenously, and of $190 \mathrm{mEq}$. of potassium orally (in addition to a diet rich in potassium), the serum sodium was only $129 \mathrm{mEq} / \mathrm{l}$ and the serum potassium only $3.1 \mathrm{mEq} / \mathrm{l}$. During the next 24 hours the concentrations of sodium and potassium in the urine (the volume of which was $1800 \mathrm{ml}$.) were $28 \mathrm{mEq}$. $/ 1$. and $24 \mathrm{mEq}$./1. respectively. After the first week the serum sodium level was usually normal although low levels (about $127 \mathrm{mEq}$./1.) were occasionally recorded. The serum calcium on 21.1.64 was 8.2 $\mathrm{mg} . / 100 \mathrm{ml}$.

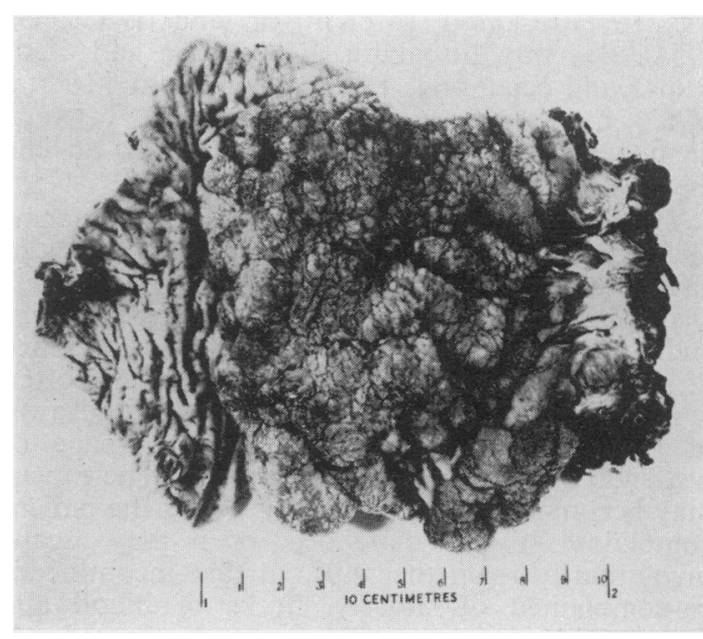

FIG. 1.

On 13.1.64 a coliform urinary infection was found, there were rales at both lung bases and chest X-ray $\infty$ showed a linear shadow at the right base. The

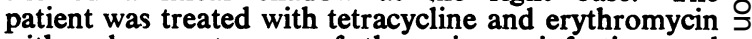
with subsequent cure of the urinary infection and clinical and radiological resolution of the pulmonary lesion. In view of persistent moderate glycosuria and of blood glucose levels between $180-300 \mathrm{mg}$. / $100 \mathrm{ml}$., soluble insulin was begun on 14.1.64 and thereafter was given subcutaneously twice daily. $\frac{0}{0}$ on

The diarrhoea continued after admission, the stoot being fluid and blood-streaked, but its severity varied from day to day. Culture of the fæces revealed no pathogens and serological tests for Salmonella and Brucella infection were negative. Owing to rectal incontinence the exact volume of fluid fæces was difficult to assess. Twenty-four hour measurements of the volume of diarrhoea included figures of 1420 ml., $830 \mathrm{ml}$., $900 \mathrm{ml}$., and $760 \mathrm{ml}$. When sigmoidoscopy was performed, a large volume of jelly-like mucus poured from the instrument before a large villous tumour was seen. Biopsy revealed no evidence of malignancy.

Despite $160 \mathrm{mEq}$. of potassium daily (in fourhourly doses of a solution prepared from the effervescent tablets of potassium B.P.C.), serum potassium concentration rarely rose above $3.3 \mathrm{mEq}$. $/ 1$., and fell on several occasions to $2.7 \mathrm{mEq}$./1. or less. The urinary concentration of potassium was not increased $(19,24$ and $11 \mathrm{mEq} . / 1$.) but the fluid stool contained $70 \mathrm{mEq}$. $/ 1$. of potassium.

In view of this difficulty in maintaining a satisfactory serum electrolyte concentration it was decided not to delay surgical resection of the tumour. This was carried out on 6.2.64, an abdomino-perineal resection of the rectum being performed because of the size of the lesion, its low situation, and the possibility of malignant change in some part of the extensive tumour. The specimen (Fig. 1) showed a large flat papilliferous growth, $6 \mathrm{cms}$. long, completely encircling the rectum with its lower edge extending to the ano-rectal junction. Histological examination confirmed that the lesion was a benign villous papilloma. On the sixth post-operative day, the abdominal wound ruptured and had to be resutured under general anæsthesia. On the fourteenth day after operation the patient suddenly became hypotensive and comatose, dying 10 hours later. 
Necropsy (Dr. K. Turk): Death was due to multiple recent pulmonary arterial emboli. There was very extensive phlebothrombosis of deep veins throughout both legs. The uterus and cervix were very small and infantile in type. The Fallopian tubes and ovaries also appeared underdeveloped. Microscopical examination of the ovaries showed absence of corpora albicantes. The pituitary, thyroid and adrenal glands were normal in size. Histologically the pituitary was normal but there was mild nodular hyperplasia of the adrenals. The pancreas contained small areas of early fat necrosis, the islet tissue appearing normal.

\section{Discussion}

The presence of hyperglycaemia and of pigmentation of the skin should have raised doubts earlier about the initial attribution of the sodium deficiency and hypotension to hypopituitarism. Nevertheless, the dramatic correction of hypotension by intravenous hydrocortisone which was seen on two occasions suggests that a functional adrenocortical deficiency existed despite the normal appearances of the adrenal glands at autopsy. The poor healing of the laparotomy wound and the areas of fat necrosis in the pancreas can probably be attributed to the very large doses of corticoids given. Even in retrospect, with more exact knowledge of the endocrine state, it is difficult to be sure that this dosage could have been avoided.

This case illustrates the difficulty in diagnosis presented by these patients who are often first seen in a state of acute peripheral circulatory failure. The presence of hypogonadism, which has not previously been described in this syndrome and which is probably coincidental, served further to confuse the diagnosis. The diabetes (the hyperglycaemia and glycosuria were present on admission and antedated the corticosteroid therapy) was probably also of no aetiological relationship to the villous adenoma or the circulatory collapse, although the patient reported by Eisenberg and others (1964) had a glucose tolerance test which 'showed diabetic tendency'. The patient described by Nelson (1963) showed hyperglycaemia but this was noticed after intravenous glucose and hydrocortisone had been given.

In addition to the 27 patients mentioned in the papers of Eisenberg and others (1964), and Shamblin and others (1962), we have found references in the literature to over 20 cases of villous tumours with serious electrolyte disturbance. It seems probable that the complication has been unrecognised rather than uncommon. It is of interest that Gabriel in 1952 mentions that 'Out of 11 cases of large benign villous tumours of the rectum treated by perineoabdominal excision there was one operative death; this occurred in a thin dehydrated patient aged 78 who died on the day after operation from cardiac failure'. Almost certainly this man suffered from the syndrome now under discussion.

\section{Summary}

The case of a woman with a large benign villous papilloma of the rectum, presenting with sodium and water depletion and later complicated by persistent hypokalaemia, is described. The patient also suffered from primary hypogonadism and diabetes.

\section{REFERENCES}

Duthie, H. L., and Atwell, J. D. (1963): The Absorption of Water, Sodium and Potassium in the Large Intestine with particular reference to the Effects of Villous Papillomas, Gut, 4, 373.

EISENBERG, H. L., KolB, L. H., YAM, L. T., and GoDT, R. (1964): Villous Adenoma of the Rectum Associated with Electrolyte Disturbance, Ann. Surg., 159, 604.

EwING, M. R. (1950): Villous Tumours of the Rectum, Ann. Roy. Coll. Surg. Eng., 6, 413.

GABRIEL, W. B. (1952): The Surgical Management of Large Villous Tumours of the Rectum, Proc. roy. Soc. Med., 45, 696.

Haverkon Van RiJsewiJk, M. J. (1961): A Patient with a Potassium-Secreting Tumour of the Large Intestine, Ned. T. Geneesk, 105, 2500.

LiTTLE, J. M. (1964): Potassium Imbalance and Rectosigmoid Neoplasia, Lancet, i, 302.

MCKITTRICK, L. S., and WHEELOCK, F. C. (1954): Carcinoma of the Colon, pp. 61-63, Springfield, Illinois: Charles C. Thomas.

NelSON, C. H. (1963): Electrolyte and Metabolic Changes in Villous Adenoma of the Colon, Amer. J. Proctol., 14, 315.

QUAIN, R. (1855): Diseases of the Rectum, 2nd Edition, p. 295, London: Walton and Moberly.

Shamblin, J. R., HuFT, J. F., WaUgh, J. M., and MOERTEL, C. G. (1962): Villous Adenocarcinoma of the Colon with Pronounced Electrolyte Disturbance, Ann. Surg., 156, 318.

SHNITKA, T. K., FRIEDMAN, M. H. W., KIDD, E. G., and MACKENZIE, W. C. (1961): Villous Tumours of the Rectum and Colon Characterized by Severe Fluid and Electrolyte Loss, Surg. Gynec. Obstet., 112,609 .

StarR, A., Mueller, S., and McKittrick, J. R. (1956): Villous Adenoma of the Colon Associated with Severe Hypopotassaemia, Arch. Surg., 73, 